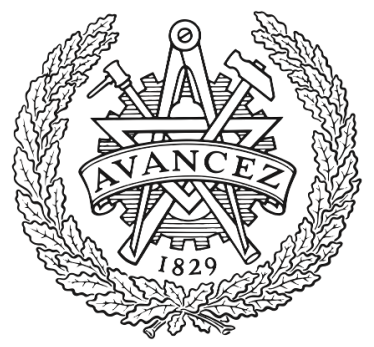

CHALMERS

UNIVERSITY OF TECHNOLOGY

\title{
Life Cycle Management of Infrastructures
}

Downloaded from: https://research.chalmers.se, 2023-04-26 08:19 UTC

Citation for the original published paper (version of record):

Wallbaum, H., Ebrahimi, B. (2019). Life Cycle Management of Infrastructures. Industry, Innovation and Infrastructure. Encyclopedia of the UN Sustainable Development Goals..

http://dx.doi.org/10.1007/978-3-319-71059-4_22-1

N.B. When citing this work, cite the original published paper. 


\section{Life Cycle Management of Infrastructures}

Holger Wallbaum, Dr.-Ing. Professor in Sustainable building, Dept. of Architecture and Civil Engineering, Chalmers Univ. of Technology, Gothenburg 412 96, Sweden. E-mail:

holger.wallbaum@chalmers.se

Babak Ebrahimi, Ph.D. Candidate in Sustainable building, Dept. of Architecture and Civil Engineering, Chalmers Univ. of Technology, Gothenburg 412 96, Sweden. E-mail: babake@chalmers.se

Synonyms:

Life cycle thinking, Life Cycle Management, Systematic approach

\section{Definition}

By a definition, life cycle management (LCM) is a framework "of concepts, techniques and procedures to address environmental, economic, technological and social aspects of products and organizations to achieve continuous" sustainable "improvement from a life cycle perspective" (Hunkeler et al. 2001). Thus, LCM theoretically integrates all sustainability dimensions and it strives to provide a holistic perspective. It also assists in efficient and effective use of constrained natural and financial resources to reduce negative impacts on the society (Sonnemann and Leeuw 2006; Adibi et al. 2015). Life cycle management of infrastructures is the adaptation of product lifecycle management (PLM), like techniques to the design, construction, and management of infrastructures. Infrastructure lifecycle management requires accurate and extensive information that might be generated through different kind of intelligent and connected information workflows, like Building Information Modelling (BIM).

\section{Introduction}

Immense negative impacts rooted in anthropogenic activities over the last couple of centuries often in literature referred to them as the outcomes of the Industrial Revolution (Mitchell 1989; Senge and Carstedt 2001; Lal 2004; Howarth 2008; Choi et al. 2009; Bose 2010) - has resulted in adverse impacts and irreversible changes to our environment and ecosystem. The urgency of adjusting the current patterns and attitudes toward the Earth has been the headlines of many discussions since 1990s (UNFCCC 2016). This in essence is due to the realization that we are reaching a saturation point and at which our planet cannot sustain itself; neither on local nor global level (Rockström et al. 2009a; Steffen et al. 2015). Hence, the future of humanity on this planet heavily depends on the path that we decide to take.

The importance of striving towards a sustainable development has been already highlighted and addressed in various global agreements related to the climate change (United Nations 1992; UNFCCC 1997, 2015), and reflected on the reports by the United Nations (UN) on the Sustainable Development Goals (SDG) to be reached by 2030, see figure 1 (United Nations 2016, 2017a). 


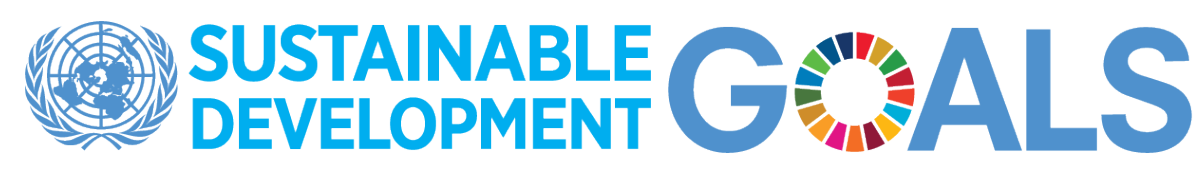
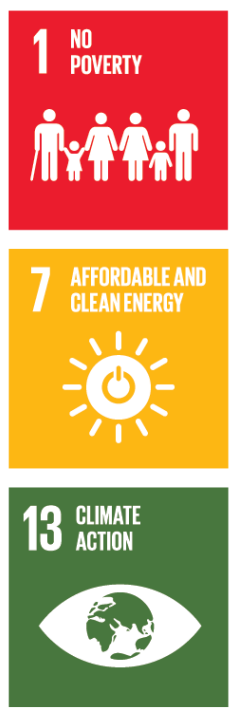
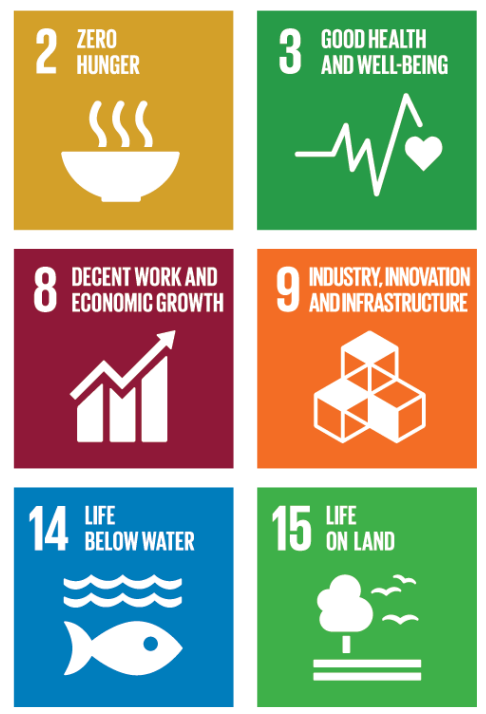
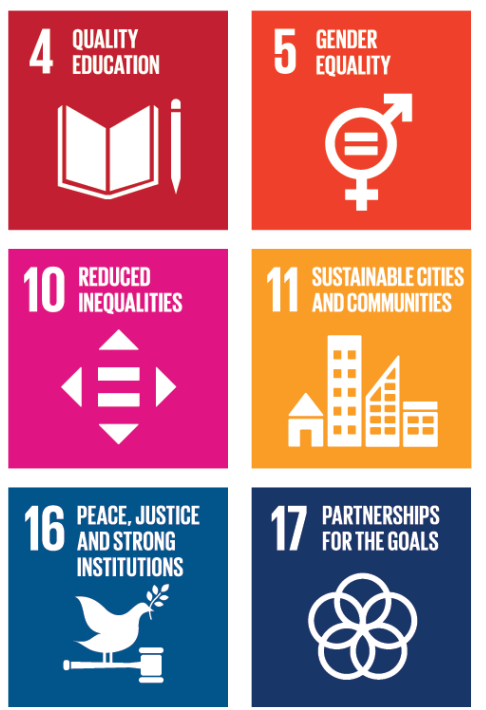
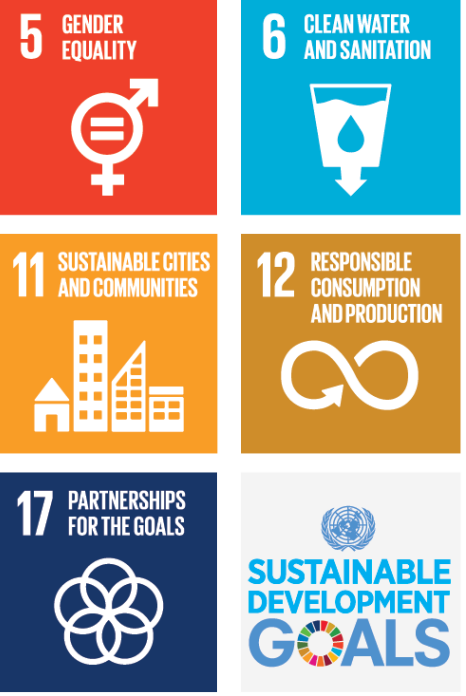

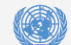

SUSTAINABLE DEVELOPMENT GALS

Figure 1: United Nations Sustainable Development Goals (United Nations 2018a).

The goal of these collective agreements has been to pin down the importance of our strategies and approaches to the extent that they should have sustainable characteristics to tackle current and future needs without compromising future generation needs and opportunities (Brundtland 1987). In this trajectory, utilization of systematic approaches and having a life cycle thinking by means of life cycle management (LCM) has been found as a powerful approach to enhance the design, planning, construction, maintenance as well as evaluation (Wrisberg et al. 2002; Sonnemann and Leeuw 2006; UNEP/SETAC 2007; Nilsson-Linden et al. 2014).

Early on, such a methodological approach had a business focus and been incorporated by small and medium-sized enterprises to support business opportunities and take informed decisions (Sonnemann et al. 2001). Despite the corporate interests, implementation and integration of an LCM framework in infrastructure developments can be considered as a continuation step and an approach to capture the long-term performance of infrastructures. This is also since the LCM of infrastructures has a different situation in terms of problem owners; most of the infrastructures are owned by public authorities or closely connected bodies. Life cycle thinking is regarded as a systematic approach to address global as well as local challenges and hence, to reach the sustainability goals with a main emphasis on the SDG goals number 9 "Industry, innovation and infrastructures", number 11 "Sustainable cities and communities" and number 12 "Responsible consumption and production".

\section{Challenges and opportunities of current and future infrastructure}

Infrastructure can be interpreted as a system, which delivers services to sustain functionality and future developments of activities within its boundary or beyond (Law 2016). There are technically various types of infrastructures with different functionalities and purposes, which can be classified into soft and hard infrastructures (Fourie 2006; Andersson and Andersson 2008). Soft infrastructures or non-material capital are those that are directed towards the societal welfare, like the educational system and the judicial system, while hard infrastructures or material capital are those that 
contribute to prompt economic activities, like transport system, built environment and communication system (Fourie 2006).

The importance of infrastructures on sustaining societal welfare, economic growth, and environmental protection has been admired and highlighted throughout the time (Sahely et al. 2005; Ugwu and Haupt 2007; Palei 2015). In fact, their significances are often characterized based on two dominant elements; capital goods - i.e. stock and flow variables - and ownership - i.e. public vs. private (Fourie 2006). These elements characterize the domain at which infrastructures involve and contribute, like high-level versus low-level infrastructure services that creates benefits for a large or small number of users.

Despite the level of infrastructure involvements, the role of infrastructures may vary throughout time and space. Depending on governing temporal and spatial conditions, different infrastructures can get different levels of importance that can be due to psychological, technological, and financial changes (Gaines 1998; Foxon 2010; Bridge et al. 2013; Axon 2017). There exist several examples of such transitions in the domain of infrastructures that were fueled by various underlaying reasons, like the example of technological shift from locomotives equipped with steam engines to electrically powered trains (Gaynor 1948), or the current transition in the European electricity grid that is shifting from fossil fuel-based power plants to renewable power generation (Jones et al. 2018). These changes often are because of limitations of prior systems that were not compatible with the demand for growth and/or because of systematic challenges that were not able to address the emerging market as the results of population growth, globalization, urbanization etc. (Group World Bank Infrastructure Strategy Committee 2015).

\subsection{Population}

Undeniable, there is a growing trend in global population and increase in life expectancy that generate impacts locally and internationally (United Nations 2015, 2017b). Various scenarios were used to project the growth expectation of the future global population and most of them have confirmed that there will be much more people on this plant by the end of this century than today, see Figure 2. 


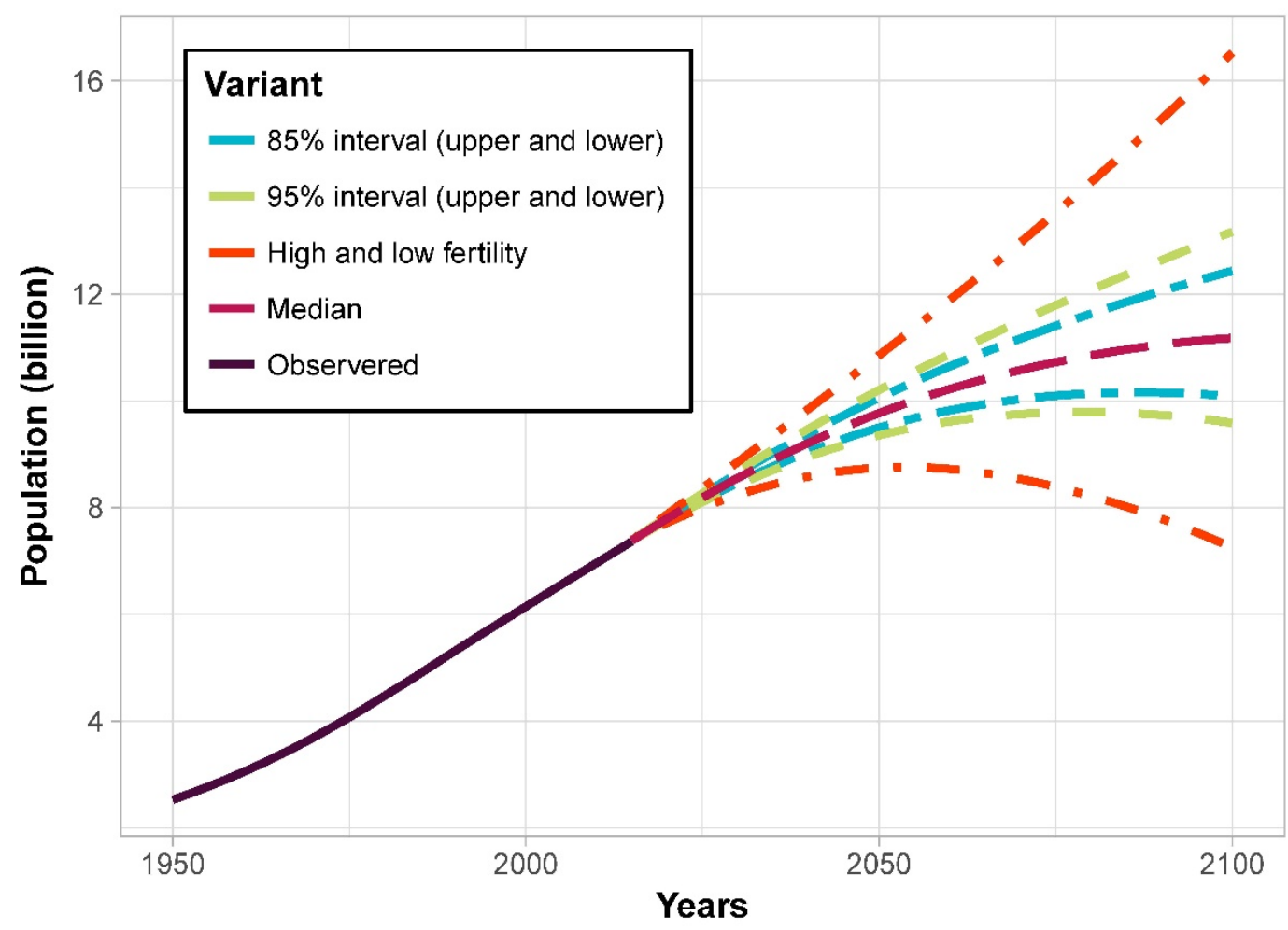

Figure 2: Probabilistic estimation of the world population trends (United Nations 2017c).

Along with the population growth and seeking for future opportunities and prosperities (Eremia et al. 2017), people and industries possibly will continue moving from one place to anothertemporarily or permanently, see Figure 3 . 


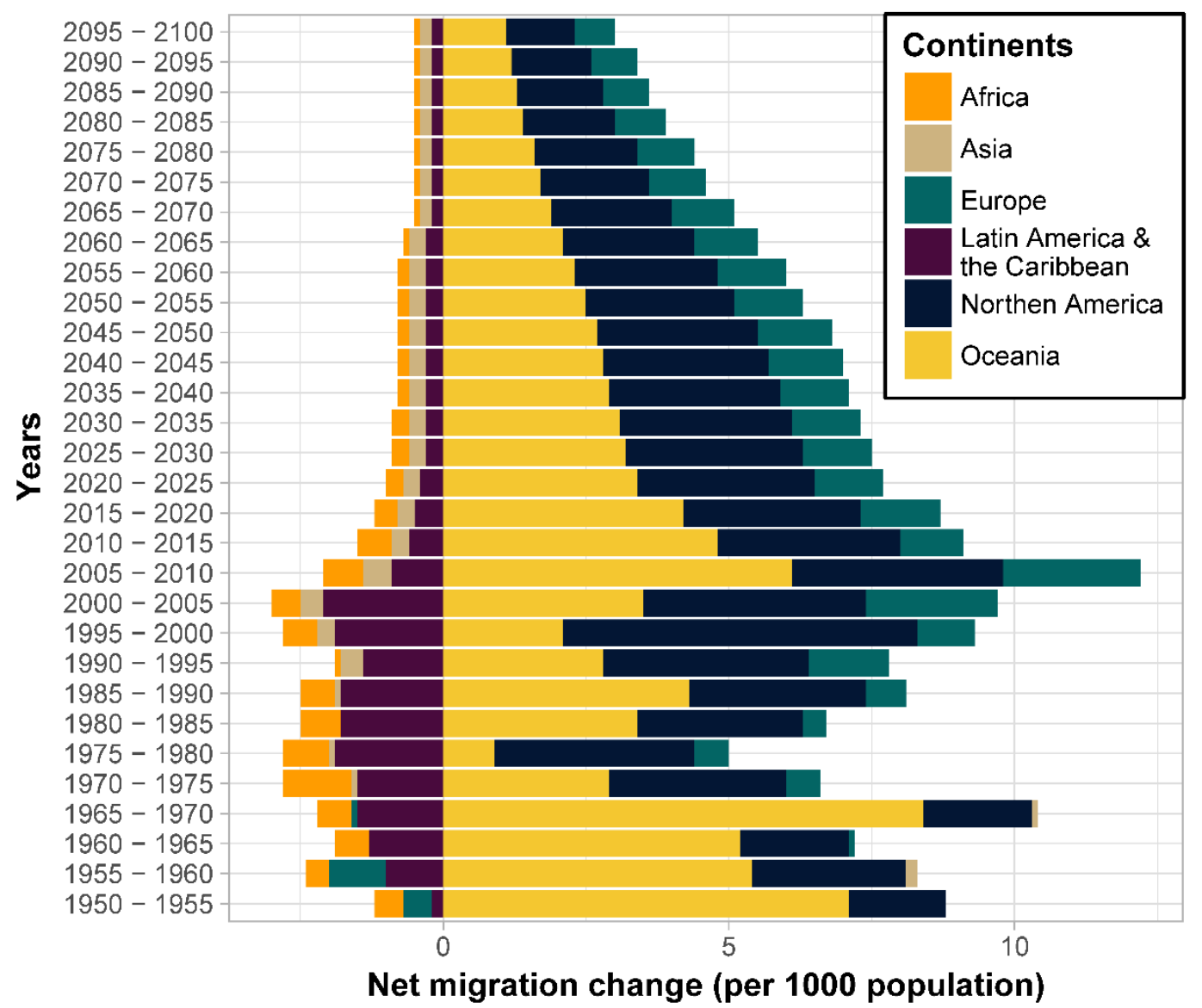

Figure 3: Projections of international migration rate (United Nations 2017c).

The spatial-temporal movements, forced or voluntary, have become a complex challenge of the current societies. This is since the direction of movements is often challenging to be planned and predicted in a long-term perspective (Bhatta 2010). In addition, the smartness of decisions on longterm effectiveness of existing infrastructures as well as new infrastructure developments is, to some degrees, linked to the growths and demands (Berger and Enflo 2017; Kaminsky and Faust 2017; Kesztenbaum and Rosenthal 2017).

\subsection{Globalization}

Alongside with the continued globalization, various socio-economic opportunities and developments arise, predominantly for those that are within the area of activities (Nelson 2005; Bharadwaj 2014). The existence of supporting domestic and international infrastructures, like transportation and communication infrastructures, is a key enabling factor to create these opportunities in the global system (UNESCAP 2007; Bharadwaj 2014). In the last two decades, the global market benefited a lot from the fact of gradual reduction in transportation and communication costs, which have eased investments and trades (UNESCAP 2007). However, globalization in unregulated and uncontrolled markets may lead to negative outbursts and negative global impacts. The global crises, e.g. the energy crisis of the 1970s, the financial crisis of 2008, ocean plastic pollution, and every now and then cybercrimes, in the past decades have shown the negative side effect of globalization (Sachs 1999; Olssen et al. 2004).

Undoubtedly, there is no universal solution to assure the global sustainability. In a way that it declares managerial practices on all levels. In spite of that, it is essential to understand the global dynamics to reduce the risk of failures and a consecutive chain of events (Reid et al. 2010) to protect 
our infrastructure systems (even though very difficult) from infringing and disruptive effects. In addition, a strong governance to monitor and control activities is essential to tackle global crises and assure prosperous growth.

\subsection{Urbanization}

Despite the future trends in global population, the speed of growth will probably change in different areas in the coming future. It is expected that we will observe a continued trend that even more people will live in urban areas than in rural areas by the year 2050, see Figure 4 (United Nations 2015, 2018b).

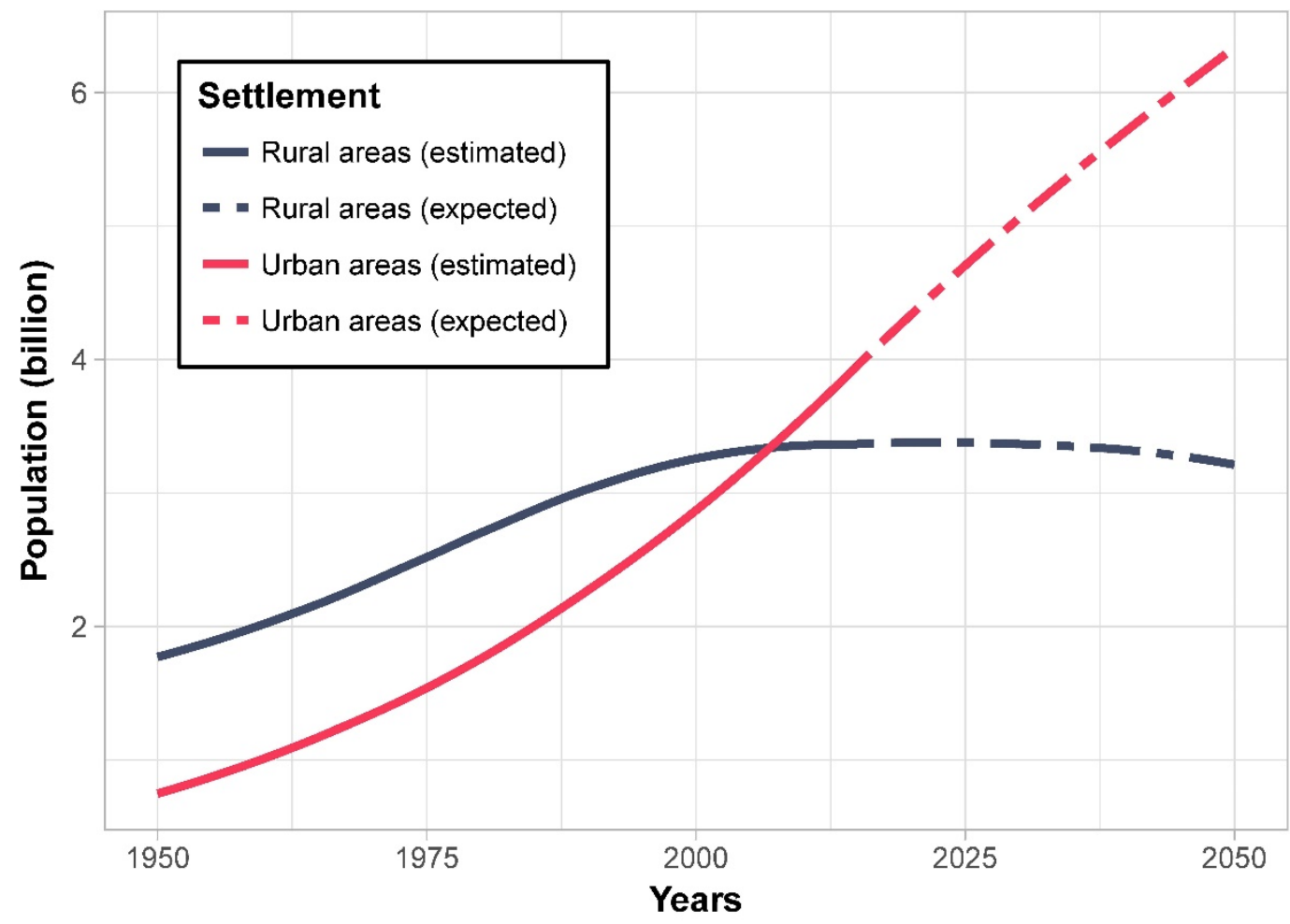

Figure 4: Trends of urban and rural populations (United Nations 2014).

This stable increase in the total share of urbanized population will put many existing infrastructures under pressure if no precautionary measure, such as proactive rehabilitation and adaptation, is set in place. In-service infrastructures will especially be challenged regarding their longevities, like shortening the designed service lives or increasing the frequency and extensiveness of maintenance activities. Adaptive measures and increased maintenance activities will very likely require the use of more natural resources that will lead to higher environmental impacts.

\subsection{Land use}

The impacts of urbanization, globalization, and higher demands on existing and new infrastructures result in densification and expansion of cities (UNFPA 2007). Whether it is because of horizontal or vertical expansion of urban and rural areas, the usage of more land and the change of types of land, such as uncultivated or farm land into land for construction activities, seems to be inevitable. Such a change is often triggered by the demands from the market as shown in studies by Pielke Sr. (2005), Lambin and Meyfroidt (2011), Meyfroidt et al. (2013), Schmidt et al. (2015), Ahlgren and Di Lucia (2016). The direct change occurs on the same land, which is currently occupied, like a change in cultivation practices or a change in types of real estate. However, the indirect change occurs due to 
upstream effects, like a transformation from a forest land to arable land or a land transformation for new settlements or industrial and economic needs (Schmidt et al. 2015).

The trend in the local and global land use and cover change has been one of the human-caused factors that has influenced on biological diversities on various regions over time (Fujisaka et al. 1998; Gutman et al. 2004; Smith et al. 2010; Newbold et al. 2015; Zhao et al. 2015; Liang and Liu 2017; Thorson et al. 2017). It is reported that the population size of vertebrate species has been cut in half over a period of 40 years of observation (WWF 2016). The changes in the land use and land cover over time has also influenced the capacity of the ecosystem to recover and to keep the biologically productivity for the sake of the humankind. Based on what has been estimated, the biocapacity of land and water has continued to decay to the extent that there is a need for more than one planet Earth to sustain the current demand, see Figure 5 (Global Footprint Network 2018). This reduction in biologically productivity of land and water paired with the raised in standard of living and consumption patterns slowed down the regenerative power of the ecosystem to retain its capacity.

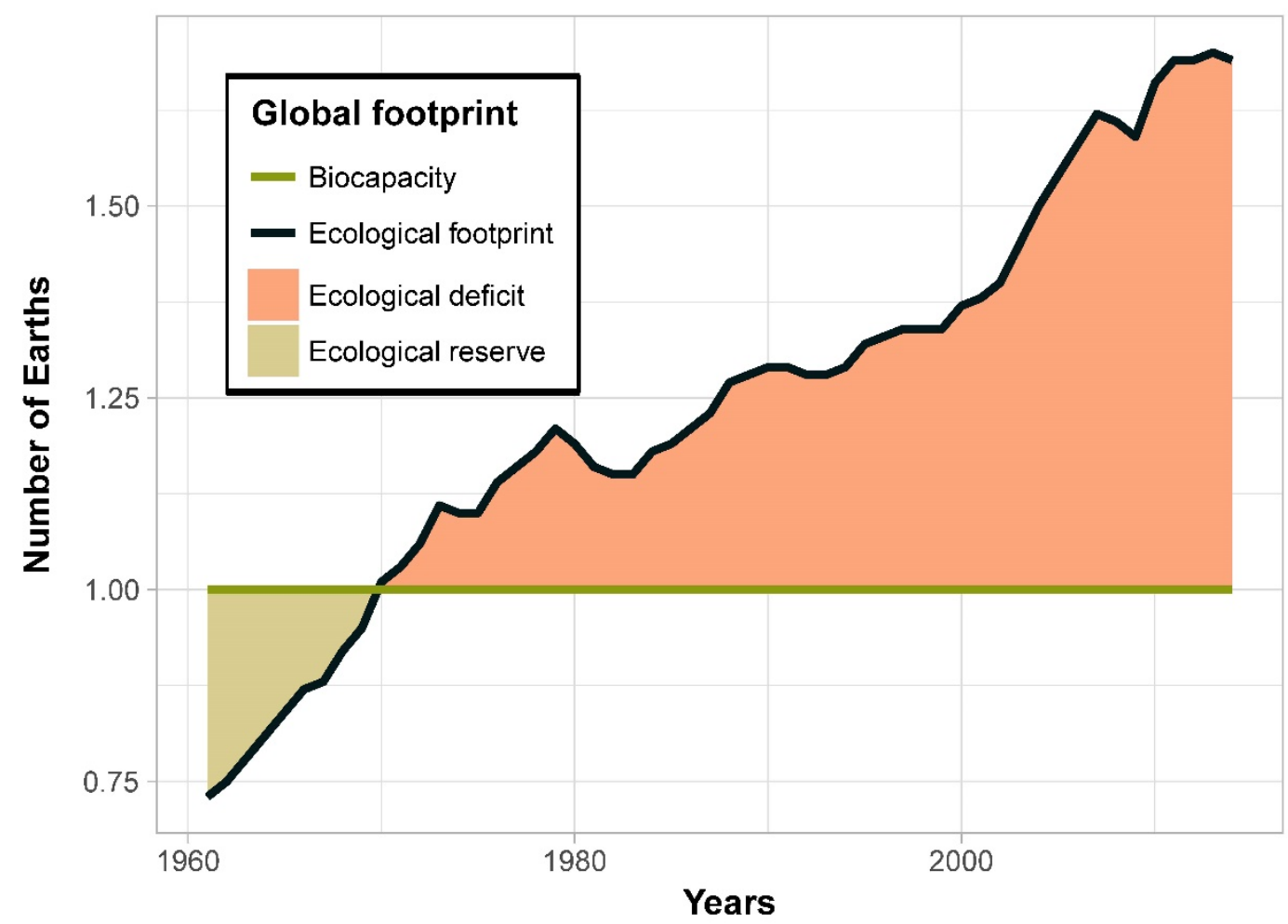

Figure 5: Global ecological footprint showing reserve/deficit trends (Global Footprint Network 2018).

\subsection{Resource efficiency}

Population growth in combination with the continued urbanization and globalization trends will require more resources to be allocated to infrastructure systems in a long-term perspective (UNEP 2011). Continuous extraction of natural resources coupled with poor management, since the beginning of the $20^{\text {th }}$ century, has made it difficult to assure their existence and availability in the future. (Nelson 2005; Humphrey et al. 2008; Rockström et al. 2009b; Fischer-Kowalski et al. 2011; Mohd Hasan and You 2015; Steffen et al. 2015; Eremia et al. 2017). In the period from 1980 to 2009, the worldwide extraction of biotic and abiotic material nearly doubled from 35 billion to 68 billion tons. At the same time, the average per capita material consumption increased by about $25 \%$, from 7.9 tons in 1980 to 9.9 tons in 2009, whereas the physical trade has been growing by 3\% annually. Considering a fair share of global material consumption per capita and expecting a continued growth 
of the world population, a sustainable or sometimes called resilient resource usage - assuming a recreation of the biological system - is far out of sight (Humphrey et al. 2008).

Hence, a resilient handling of the natural resources has been put on the agenda of various governmental bodies, with the earliest lose regulatory offspring's already in the 90ies in Europe. Since then, statistical methods have been agreed upon to measure the usage - sometimes also called "consumption" - per country, sector or even capita. A few countries as well as the European Union have introduced national goals regarding an efficient use of national resources (European Commission 2011; Ekins et al. 2017), and the United Nations Environmental Programme (UNEP) resource panel has been installed aiming at reducing the usage of virgin materials and supporting a circular economy approach (Liu and Müller 2013; Milford et al. 2013; Pauliuk et al. 2013). The concept of Material Passports is also another example of such initiatives aiming at increasing the circularity of materials in the built environment by means of the Building Information Model (BIM) (EPEA Nederland BV 2017).

\section{Life cycle of infrastrctures}

Life cycle of any new infrastructure, in most cases, begins with an initiation that declares the aim at investing in a new infrastructure and continues with intensive planning and design processes, execution, operation, maintenance activities and end-of-life phases (Winch 2003; Larsson 2012; Krantz 2017). These phases are most often follow a consecutive order, as the output from one phase is the input for the next, see Figure 6 . However, by its nature, the lifecycle principle follows an iterative approach to assure the viability of decisions in each phase. In some instances, it might be the case that it is necessary to take one or more steps backward to restructure or reevaluate the chosen approach. Alongside these phases, a series of studies, discussions, stakeholder dialogues and consultations of several institutional entities take place. The existence of these bodies is essential to assure the successfulness of the infrastructure and to achieve comprehensive outcomes.

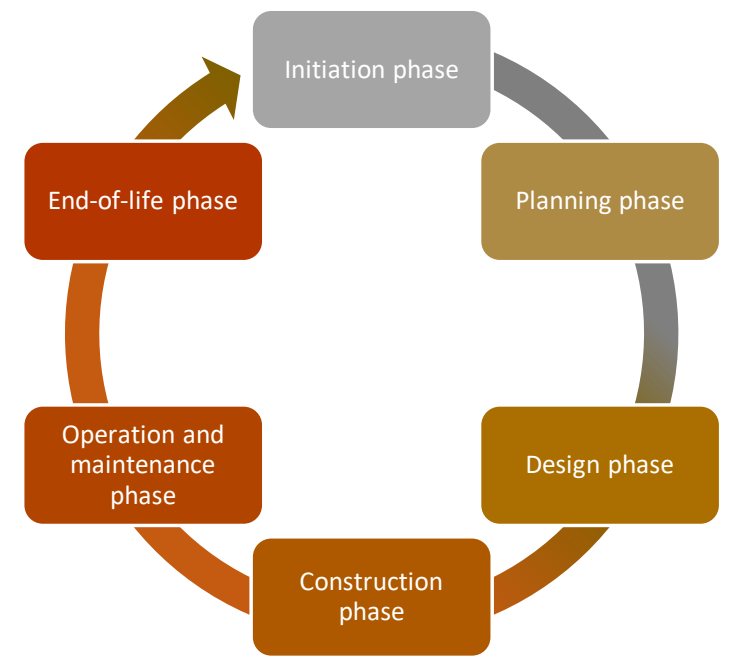

Figure 6: An abstract view of the life cycle of an infrastructure project.

\subsection{Initiation phase}

The goal of any infrastructure developments is to be successful, tackle the project objectives and has positive contributions, while reducing negative impacts. To meet these fundamental goals, it is essential to know the potential outcomes of an infrastructure development. This is often formulized and answered whether it is necessary to invest on a new infrastructure project, or maintenance/rehabilitation of current infrastructures are potentially a more advantageous 
approach; in some cases, more can be obtained by optimum maintenance planning of the existing infrastructures rather than investing on new projects (Dobbs et al. 2013).

The tradeoff of the decisions at the end lays on the objectives and the perspectives that it aims to accomplish. Feasibility studies are conducted during this phase to justify the impacts of the infrastructure project to make wise decisions and get the project approved for the investment. Performing feasibility studies on narrowly defined objectives, have possibly a counter effect on achieving the SDGs. This is since these kinds of feasibility studies are unable to have a holistic overview of the project to understand the magnitude of their impacts, like the effects of the project on the network and the metabolism of the system. Hence, the implementation of sustainability assessments is essential to provide coherent approach to evaluate the potential impacts of a projects.

At the same time, the role of shareholders and stakeholders, and their involvements in the early stage of a decision often reduce implementation of unsustainable measures that later on will be planned and executed (Lenferink et al. 2012). The early involvement in the front end of an infrastructure project is likely to assist in providing a balance among economic, social, and environmental measures over the entire lifecycle of the infrastructure.

\subsection{Planning phase}

Infrastructure planning processes manage the scope of the project to meet the initiated objectives. They identify and map necessary resources, e.g. financial, material, and labor, necessary throughout the project. They also outline the sequences of activities over the portfolio of the project by declaring the tasks and duties. Such coordinated planning processes for new infrastructures; however, can mainly be expected in countries with a well-functioning legislations and institutional set-ups on all levels from municipality, over the region, and up to the national level. During or after a crisis and in countries with a less established regulatory framework, not all infrastructure related processes achieve this level of proficiency. This implies that countries affected by war or on the verge of economic development might often skip some of the preliminary phases due to time and financial constraints. Such occurrences often result in the construction of infrastructures with standards or performance qualities far below the state-of-the-art, which in a long-term perspective is disadvantageous for various reasons, e.g. higher life cycle costs, frequent maintenance demand with negative consequences for the users of any such an infrastructure, increased safety risks for workers and users, a higher consumption of natural resources etc.

\subsection{Design phase}

Until the design phase of an infrastructure project, many detail parts are often unknown. These hidden aspects require investigations and open discussions to be unlocked in order to reach to the final design (Eriksson 2013). These discussions are very cursorial, especially for the state-of-the-art infrastructure developments where the largescale or the real-world version of the infrastructure has not been built yet and the future success of the project lays beneath large uncertainties. Inclusion of actors, decision makers and contractors to integrate their expertise into the project development potentially help to solve some of these misapprehensions.

Infrastructures are designed to last for decades with optimum performance to reduce any unforeseen events and do not results in adverse effects. The design criteria for most infrastructures, in well-established projects, follow certain criteria to assure their performance over a certain analysis period. Often the selection of the analysis period is defined shorter than the expected lifetime of the infrastructure (Gschösser and Wallbaum 2013). This approach potentially diminishes 
the comprehensiveness of the study and disregards the lifecycle thinking of the infrastructure project.

\subsection{Construction phase}

The goal of achieving a sustainable construction practices is to find a trade-off between economy, society and environment, while fulfilling technical and functional performances. Business-as-usual practices by the construction industries should not be a prescribed approach because of its establishment and lower risks during the construction phase of a project. Instead, this sector should attempt to implement sustainable initiatives in their long-term business strategies to restore their values and responsibilities toward the society and environment. Green public procurement and environmental product footprint are two instruments that encourages businesses to set new norms for their practices.

Alongside the innovations that can be harnessed by the construction sector, the owners of infrastructure projects can change their contracting practices. As a potential approach, a selected construction contractor should be also assigned as the responsible body for the future maintenance activities of the infrastructure project. This practice will probably shift the traditional approach, which have segregated the construction from the maintenance contracting. It in fact assures that the contractor will be responsible for the quality of the work to reduce the frequency and the intensity of maintenance works.

\subsection{Operation and maintenance phase}

This is the phase which all infrastructures are built for and expected to provide the expected service. Most of infrastructures are designed to withstand a long service lives with optimum performance. Although infrastructures, in well-regulated nations, are designed and executed based on standards and directives, they have been continuously aged and distressed since they began their service. The backlog and deficits of maintenance activities throughout time has exceeded in many economies (Dobbs et al. 2013). This is to the extent that they have violated the capacity of infrastructures and resulted in disorder and more extensive maintenance activities, as well as more capital expenditures.

Monitoring long-term performance of infrastructures is a potential way to investigate details that are critical to evaluate infrastructure performance. The obtained inputs can be used to validate the performance of the infrastructures based on prior designs and identify influential variables. The generated results can be used to optimize maintenance planning to lessen the frequency and intensity of maintenance activities, while increase reliability and capacity of infrastructure.

In addition, auditing of the success rate of a project is essential in this phase. This helps to evaluate the initial understanding that were justified in the beginning of the project development. It assists in tracking lessons learned and identify potential pitfalls in the prior decisions and processes. It highlights how close to reality the project was assessed; over- or underestimate the potential impacts of the project. The auditing of the project can be also seen as a potential case study that the findings from it can be used for the future projects.

\subsection{End-of-life phase}

The end of an infrastructure lifetime finalized by a decommissioning phase to reduce risks of unexpected failures followed by minimizing costs and other negative impacts. The next journey of used materials after the decommission heavily depends on how thoroughly the materials were selected, installed, and documented over the lifecycle of the infrastructure. Upcycling and/or downcycling of materials in this phase is determined by the documentation and the quality of 
dismantled materials. Poor documentations and low quality of material separations and sorting result in loss of materials in the next cycles, while increasing landfilling and extraction of raw materials.

In addition, this phase of the lifecycle is typically excluded from the sustainability assessments of an infrastructure project, which often need to be performed during the planning and design phases of the project. The exclusion of this phase has been the common practice and it has been argued due to the long technical lifetimes of infrastructures that increased uncertainties of the assessments. This was a likewise approach taken for the electrical and electronic equipment (EEE). However, the large growth in the production and utilization of the EEE followed by mishandling them at the end of their lifetimes showed that the necessity of inclusion of full life cycle analyses of such products. Although it can be argued that the technical lifetimes of electrical equipment are not comparable with infrastructures, the capacity and the quality of service that infrastructures deliver heavily depend on maintenance works during their lifetimes. This in a sense shows the evidence that the relative longer lifetimes of infrastructure should be compromised with more material use and disposal. Therefore, it is necessary to include the end-of-life phase in the early stage of a project to choose materials with high circularity capacities and design infrastructures modularly to increase replacement/disassembling speed and at the same time increase recyclability of materials.

\subsection{Reliability and uncertainties}

Regardless of the phase of an infrastructure project, the role of stakeholders on the final decisions may result in foreseen and/or unforeseen outcomes. Flaws in human decisions are not new phenomena and they have been observed and documented in history books and integrated in new design guidelines. As the infrastructure systems expands and the demand and utilization on the infrastructure grow, human errors may outburst vulnerabilities of the society and economy and may slow down the pace toward achieving the sustainability goals, and in some extreme cases makes it unreachable.

Uncertainty and variability can arise in any stages of the lifecycle that root to lack of certainties about the true impacts of decisions or designs and they can be qualitatively or quantitively measured (Björklund 2002). Uncertainties in most cases are due to human failures, as it may occur through data inaccuracy, data gaps, unrepresentative data, model uncertainty etc. (Elishakoff 1995) Although uncertainties can be dealt by improving knowledge and collection of advance and representative data, variability cannot be reduced by further measurements because of inherent variations in the real world (Huijbregts 1998; Björklund 2002). Even though infrastructures in Japan are designed to withstand high impacts from earthquakes, unpredictable events may happen. The tsunami of 2011 in Japan (Oskin 2017), is an example that showed extreme outliers may happen as a result of variability in reliability of designs.

In fact, not all unexpected events occur due to human failures as just mentioned in the case of the Tsunami in Japan. As another source of insecurity, natural disasters are a rather frequent cause of infrastructure damages and failures with severe consequences. In comparison to the very suddenly happening events of thunderstorms, fires, earthquakes etc., climate change is happening gradually. It is to a very large extent scientifically proven that climatic patterns on the globe has been changing and as a result more extreme weather events will be expected to occur (IPCC 2007, 2012). In other words, it is expected that as the result of climate change the global average temperature will increase, frost-free seasons will be prolonged, precipitation patterns will be changed, drought, heatwaves and hurricanes will hit different areas on the globe, sea-level will rise, glaciers and sea ice 
will shrink (NASA 2018). These changes in the climatic patterns will result in more or less larger consequences for the various infrastructures.

The externality of such humanitarian activities and the damage costs from unabated climate change are expected to be huge (Ciscar et al. 2011; Tol 2018), if no adaptation measures are set in place. Resilience - in terms of the capacity of an infrastructure to withstand perturbations without losing their technological-functional reliability - of the infrastructure in coming years heavily depends on how the climate adaptation measures are going to be addressed in the design, construction and maintenance of any infrastructures. In addition, it is necessary to identify the likelihood of risks and try to harness/bypass them in hazardous areas to reduce infrastructure losses and their negative impacts on the society, the economy and the environment (Ebingner and Vandycke 2015). Examples of such adaptive measures are, e.g. the identification of susceptible soils to landslides and relocation or strengthen the subsoil and infrastructure (Dias et al. 2017), the prediction of flood prone areas and enhancement of the drainage water system (Chang et al. 2013), or the estimation of the impacts from the mean sea-level rise on ocean tidal amplification, coastal structures, and ecosystem (Devlin et al. 2017).

\section{Implementation of life cycle management in Infrastructure}

Utilization and implication of LCM in different areas of researches as well as in practice have been constantly increasing (Sonnemann and Leeuw 2006; Nielsen et al. 2013; Barone et al. 2014; Glisovic et al. 2015; Sonnemann and Margni 2015) and this approach has been used for different purposes and emphases, e.g. some with the focus on the economic performance and other with the focus on environmental impacts. Such variations in the points of views, highlighted the shortcoming of having a common ground that could explain the purpose of a managerial practice from a life cycle perspective. As it was addressed by Sonnemann et al. (2015), the term LCM in the earlier works were skewed more toward the environmental aspects and it had rather a weak sustainability perspective. However, the terminological and conceptual developments by different authors in the domain of LCM made it a more comprehensive perspective to address the triple bottom lines.

Assessment methods and tools to quantify the sustainability impact of decisions from the LCM perspective heavily depends on the contextual level - political vs. modelling context - and the phase at which a project is placed - initiation phase vs. operation and maintenance phase (Sonnemann et al. 2015). If an infrastructure project is in the early phase of a decision-making process, like a feasibility study, utilization of holistic assessments may provide a clear picture of impacts associated with different options to understand pros and cons of decisions. It may declare to what extend an infrastructure project is going to be successful from a sustainability point of view - applying technical, functional, environmental, economic and social indicators. In addition, the LCM provides insightful use for in-service infrastructures. So that it supports the decision-making works for the maintenance and rehabilitation works based on available solutions to assure the robustness of approaches in the framework of sustainability. This approach will eventually increase the capacity of infrastructures, while reducing the frequency and the intensity of preservation and upgrading activities (Dobbs et al. 2013).

The purpose of life cycle thinking is to avoid taking sub-optimization decisions that might lead to problem shifting. LCM is an overarching framework that incorporates various dimensions of sustainability within its system boundary. The application of LCM in practice should help to reach a level of facts that support decision makers in taking conscious decisions. In this trajectory, different methods and tools have been developed and are available to support different stakeholders in applying the LCM approach. Life cycle assessment (LCA), material flow accounting (MFA), input- 
output (IO) analysis, life cycle costing (LCC), social life cycle assessment (SLCA), and risk analysis (RA) are the most discussed methodological approaches in a large list of assessment schemes that can be used for the LCM purposes (Sonnemann et al. 2015).

Alongside the realization in providing a systematic approach to assess sustainability of infrastructures, the European Committee for Standardization (CEN) has set up the Technical Committee 350 - Sustainability of Construction works (CEN 2018). This work was initiated with the goal to provide specific principles and requirements for the assessment of environmental, social and economic performance of civil engineering works, while considering its technical characteristics and functionality. The framework applies to all types of civil engineering works, both new and existing, and it is relevant for the assessment of the environmental, social and economic performance of new civil engineering works over their entire life cycle, and of existing civil engineering works over their remaining service lives and the end of life stage, see Figure 7.

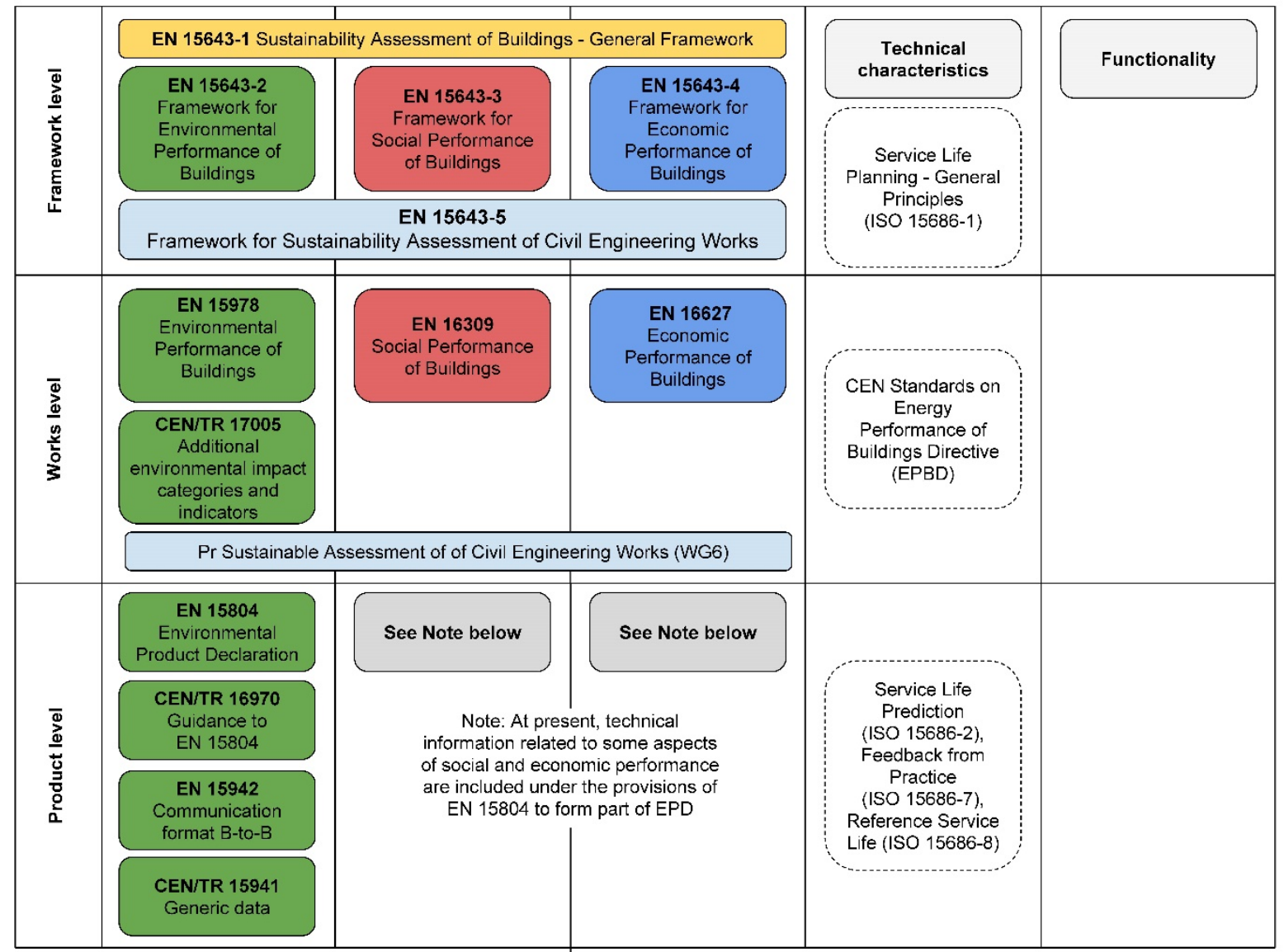

Figure 7: Overview of the standard CEN/TC 350, based on CEN (2018).

The sustainability performance assessment in the standard CEN/TC 350 concentrates on the assessment of aspects and impacts of civil engineering works. It expresses the results in quantifiable indicators that will eventually allow different stakeholders to manage their infrastructures and taking into consideration a life cycle perspective. So far, the EN 15643-5:2017 has been launched in 2017 that is focusing on civil engineering works (CEN 2017). The European Standards developed under this framework do not set the rules for how the different assessment methodologies may provide valuation methods; nor do they prescribe levels, classes or benchmarks for measuring performance. 
Along with the lifecycle tools and standards, availability of data is of great importance to enhance the robustness of assessments. In this regard, various commercial, national, and inhouse databases and handbooks, e.g. ecoinvent (2018), Exiobase (2015) and the ILCD handbook (EC et al. 2010), have been developed or are under development with different resolutions and representations. This comes to a point that the comprehension of such databases may question the accuracy of results. In the era of digitalization and availability of data, it is essential to be aware of the quality and the comprehensiveness of the data. This specially becomes of even higher importance when data from different sources are going to be used. In other words, there is an obvious risk that collecting and applying information from different sources of data may result in faulty practice of accounting in any assessments. This in most cases is because of a potential overlapping nature of databases, which often have different system boundaries. Therefore, special attentions need to be paid to such a matter and this calls for a high transparency on data sources used, system boundaries applied, data representativeness etc. and comprehensive documentation in all phases of planning, design, construction and maintenance.

Applying the LCM approach is inevitably an inter-disciplinary, and sometimes, a trans-disciplinary work. It requires expertise from various fields and multiple open dialogues to address the implications of potential decisions and possible approaches. This is essential, as different decisions may offspring different consequences or rebound effects (Hertwich 2008). There are coming more promising examples on infrastructure projects that pay attention to the importance of inter-and trans-disciplinary works. These kings of projects practically strive to benefit from knowledge on current practices and state-of-the-art research to map the impacts associated with future infrastructure investments, e.g. on demography, environment, socio-economy of region, and network level. The coastal highway route E39 in Norway (NPRA 2018a) is an example of a mega infrastructure program that use the knowledge from different schools of expertise to address current and future road infrastructure planning (Adl-Zarrabi et al. 2016; Dunham 2016).

Computational advancements parallel with the comprehension of databases in the last couple of years have opened a window of opportunities to perform more comprehensive analyses on various levels including infrastructures. They have also made it possible to perform lifecycle-based assessments for different dimensions - economic, environmental, and/or societal aspects - and identifying potential impacts. The optimization programming language (OPL) has taken the advantage of the computational advancement and assists in performing complex mathematical optimization models. Integration of LCM in the OPL has brought the benefits of performing multiobjectivity analyses to understand the optimization processes of results based on different objectives and constraints, e.g. (Lee et al. 2012; Wu et al. 2012; Abu Samra et al. 2018; Santos et al. 2018).

Data availability has also opened a door to better understand infrastructure systems in a complex network. This makes it easier not only to support the development of new infrastructures considering the entire life cycle but also to more realistically combine, plan, and assess maintenance activities of existing infrastructures. To this end, different management systems have been stablished by different governmental bodies for different infrastructures to support this intension, like BaTMan (STA 2018a) and BRUTUS (NPRA 2018b) bridge management systems, and PMSV3 (STA 2018b) and PMS 2010 (NPRA 2010) pavement management systems. The main purpose of these systems is to continuously monitor and ensure the structural health of civil engineering works to reduce failure probabilities, costs and negative social and environmental impacts. 


\section{Future direction}

Exponential growth in generated data in the network of infrastructure systems, emphasis on the importance of digital transformation, which in return can result in development of smarter infrastructure solutions. In a sense that the digital platform will potentially transform the collected data into values, which assist in achieving the SDGs. The transformation in other words helps to reshape the traditional business practice by deepening the interconnectivities, while reduces risks, strengthen efficient and effective use of resources, and enhance innovative solutions (European Commission 2018). Big Data, BIM, and cloud services are the expected trends in the direction of digitalization to add additional dimensions to the current system.

The topic of sustainability has become the headline of many reports and requirements by public and private sectors, as they strive to translate current challenges into business opportunities, while safeguarding the pace toward the SDGs. Despite the trend, headed towards the SDGs, the existence of inhouse knowledge and skills within each organization is essential. This will not be attainable without continuous vocational training, as it provides a solid foundation to integrate sustainable perspectives with skill developments to bridge the knowledge gaps and develop the systematic thinking. The vocational training is essential for both the client and owner sides to increase the competences and strategies to achieve successful and sustainable solutions (Abanteriba 2006). In addition, the current education system needs to upgrade its syllabus to educate the students of todays to be the professional graduates of tomorrow (Devon and Liu 2002). This comes to the extent that the educators are required to enrich the sustainability dimensions of curriculums parallel with pedagogical development to assure that the graduates will be able to transfer their knowledge and skills to their future carriers and act as active agents and contribute for their societies (Bridges and Wilhelm 2008).

The utilization of lifecycle based tools combined with the OPL allow basing decisions on solid foundations. However, the generated results are often incapable to fully capture the potential impacts of all product systems in an infrastructure development. This limitation is practically sourced from the existing databases that have not been fully developed yet and sometimes not being a representative of temporal-spatial changes. Continuous increase in the availability of data will likely resolve the current limitation in the databases. Nevertheless, it requires standardized approach for the management of the data so as it assures the data quality and the transparency of the collected data. The standardization is crucial to secure the systematic and the methodological approach in the collected data to eliminate inconsistencies. Furthermore, the existence of more open-access databases that will continuously updated and peer reviewed on a cloud server, is the direction that will remove barriers in commercial databases and promote reusability of data.

Sustainable innovative solutions are often directed toward a niche with a purpose to solve problems which are, for example, triggered by incentives (environmental, economic, or societal geared), law enforcements, and entrepreneurial activities (Kemp et al. 2001). In that respect, the success rate of any innovations is time dependent and tightly linked to the existing technological systems, available infrastructures, and societal willingness, to the extent that they define if a transition would happen in the current system and if so to what degree (Kemp et al. 2001; Lopolito et al. 2013).

There are handful of prosperous and unsuccessful instances in the literature showing how new technological developments, according to their initial niches, were perceived, approached and resulted (Schot et al. 1994; Van Den Ende and Kemp 1999; Truffer et al. 2002; Raven 2004; Verbong and Geels 2007; Lopolito et al. 2011). The reasons for the failures in new technological developments, based on what Schot and Geels (2008) expressed as the valley of death, is because of 
lack of linkages between the internal niche mechanisms and the social-technical transition pathway. This means the journey of any cutting-edge technological developments begins by niches and experimental practices; however, the initiation should not be built in isolations, like inside a laboratory. Instead, they should be able to communicate with external processes to be fruitful.

The agent-based modelling ( $A B M$ ) has gained momentum in the domain of emerging innovations and technologies in complex systems (Lopolito et al. 2013). This has been because of the flexibility of the computational model to address potential impacts of different decisions based on involving entities - i.e. agents. This implies that the ABM creates an abstraction model of the real world based on a network of agents that demonstrates synergies and interaction behaviors between them in the system. The ABM may potentially help to overcome the underlying limitations in the current LCM tools and make it possible to assess system behavior and effectiveness of an innovation or a sets of strategies (Berman et al. 2004; Heshmati and Lenz-Cesar 2015).

\section{References}

Abanteriba S (2006) Development of strategic international industry links to promote undergraduate vocational training and postgraduate research programmes. Eur J Eng Educ 31:283-301. doi: 10.1080/03043790600644412

Abu Samra S, Ahmed M, Hammad A, Zayed T (2018) Multiobjective Framework for Managing Municipal Integrated Infrastructure. J Constr Eng Manag 144:4017091. doi: 10.1061/(ASCE)CO.1943-7862.0001402

Adibi N, Pasquet V, Roy A, et al (2015) Life Cycle Management. 79-90. doi: 10.1007/978-94-0177221-1

Adl-Zarrabi B, Ebrahimi B, Hoseini M, et al (2016) Safe and Sustainable Coastal Highway Route E39. Transp Res Procedia 14:3350-3359. doi: 10.1016/j.trpro.2016.05.286

Ahlgren S, Di Lucia L (2016) Erratum to: Indirect land use changes of biofuel production - a review of modelling efforts and policy developments in the European Union. Biotechnol Biofuels 9:40. doi: 10.1186/s13068-016-0459-4

Andersson DE, Andersson ÅE (2008) Infrastructural change and secular economic development. Technol Forecast Soc Change 75:799-816. doi: 10.1016/j.techfore.2007.08.003

Axon S (2017) Relocation, relocation: perspectives on the spatio-temporal impacts of health services transitions. Geogr J 183:272-284. doi: 10.1111/geoj.12214

Barone G, Frangopol DM, Soliman M (2014) Optimization of Life-Cycle Maintenance of Deteriorating Bridges with Respect to Expected Annual System Failure Rate and Expected Cumulative Cost. J Struct Eng 140:4013043. doi: 10.1061/(ASCE)ST.1943-541X.0000812

Berger T, Enflo K (2017) Locomotives of local growth: The short- and long-term impact of railroads in Sweden. J Urban Econ 98:124-138. doi: 10.1016/j.jue.2015.09.001

Berman M, Nicolson C, Kofinas G, et al (2004) Adaptation and sustainability in a small arctic community: Results of an agent-based simulation model. Arctic 57:401-414. doi: $10.2307 / 40512643$

Bharadwaj A (2014) Reviving the Globalization and Poverty Debate: Effects of Real and Financial Integration on the Developing World. Adv Econ Bus 2:42-57. doi: 10.13189/aeb.2014.020107

Bhatta B (2010) Analysis of Urban Growth and Sprawl from Remote Sensing Data. Springer Berlin Heidelberg, Berlin, Heidelberg 
Björklund AE (2002) Survey of approaches to improve reliability in Ica. Int J Life Cycle Assess 7:64-72. doi: $10.1007 /$ BF02978849

Bose B (2010) Global Warming: Energy, Environmental Pollution, and the Impact of Power Electronics. IEEE Ind Electron Mag 4:6-17. doi: 10.1109/MIE.2010.935860

Bridge G, Bouzarovski S, Bradshaw M, Eyre N (2013) Geographies of energy transition: Space, place and the low-carbon economy. Energy Policy 53:331-340. doi: 10.1016/j.enpol.2012.10.066

Bridges CM, Wilhelm WB (2008) Going beyond green: The "why and how" of integrating sustainability into the marketing curriculum. J Mark Educ 30:33-46. doi:

10.1177/0273475307312196

Brundtland GH (1987) Our Common Future - Brudtland Report

CEN (2018) CEN/TC 350 - Sustainability of construction works. https://standards.cen.eu/dyn/www/f?p=204:7:0::::FSP_ORG_ID:481830\&cs=181BD0E0E925FA 84EC4B8BCCC284577F8. Accessed 4 Jun 2018

CEN (2017) Sustainability of construction works - sustainability assessment of buildings and civil engineering works - Part 5: framework on specific principle and requirement for civil engineering works

Chang H-K, Tan Y-C, Lai J-S, et al (2013) Improvement of a drainage system for flood management with assessment of the potential effects of climate change. Hydrol Sci J 58:1581-1597. doi: $10.1080 / 02626667.2013 .836276$

Choi S, Drese JH, Jones CW (2009) Adsorbent materials for carbon dioxide capture from large anthropogenic point sources. ChemSusChem 2:796-854. doi: 10.1002/cssc. 200900036

Ciscar J-C, Iglesias A, Feyen L, et al (2011) Physical and economic consequences of climate change in Europe. Proc Natl Acad Sci 108:2678-2683. doi: 10.1073/pnas.1011612108/-

/DCSupplemental.www.pnas.org/cgi/doi/10.1073/pnas.1011612108

Devlin AT, Jay DA, Zaron ED, et al (2017) Tidal Variability Related to Sea Level Variability in the Pacific Ocean. J Geophys Res Ocean 122:8445-8463. doi: 10.1002/2017JC013165

Devon R, Liu J (2002) Global change and the management of engineering education. 1:85-90

Dias AS, Pirone M, Urciuoli G (2017) Review on the Methods for Evaluation of Root Reinforcement in Shallow Landslides. Adv Cult Living with Landslides WLF 2017 Springer, Cham 641-648. doi: 10.1007/978-3-319-59469-9

Dobbs R, Pohl H, Lin D-Y, et al (2013) Infrastructure productivity: how to save \$1 trillion a year

Dunham KK (2016) Coastal Highway Route E39 - Extreme Crossings. Transp Res Procedia 14:494498. doi: 10.1016/j.trpro.2016.05.102

Ebingner JO, Vandycke N (2015) Moving Toward Climate-Resilient Transport The World Bank's Experience from

EC, JRC, IES (2010) International Reference Life Cycle Data System handbook: General guide for Life Cycle Assessment - Detailed guidance. Publications Office of the European Union, Luxembourg

Ecoinvent (2018) About ecoinvent. https://www.ecoinvent.org/about/about.html. Accessed 10 Jun 2018

Ekins P, Hughes N, Bringezu S, et al (2017) Resource Efficiency: Potential and Economic Implications 
Elishakoff I (1995) Essay on uncertainties in elastic and viscoelastic structures: From A. M. Freudenthal's criticisms to modern convex modeling. Comput Struct 56:871-895. doi: 10.1016/0045-7949(94)00499-S

EPEA Nederland BV (2017) Framework For Material Passports. 125

Eremia M, Toma L, Sanduleac M (2017) The Smart City Concept in the 21st Century. Procedia Eng 181:12-19. doi: 10.1016/j.proeng.2017.02.357

Eriksson TAS (2013) Organising the Early Design Phase in a Large Infrastructure Project. Dep Technol Manag Econ Licentiate:

European Commission (2011) Communication from the Commission to the European Parliament, the Council, the European Economic and Social Committee and the Committee of the Regions. Roadmap to a Resource Efficient Europe. COM(2011) 571final 1-26

European Commission (2018) Big data and digital platforms. https://ec.europa.eu/growth/industry/policy/digital-transformation/big-data-digitalplatforms_en

European Commission (2017) Future and emerging technologies: investing in Europe's future, improving people's lives. https://ec.europa.eu/commission/commissioners/20142019/ansip/blog/future-and-emerging-technologies-investing-europes-future-improvingpeoples-lives_en

Exiobase (2015) About Exiobase. https://www.exiobase.eu/index.php/about-exiobase. Accessed 10 Jun 2018

Fischer-Kowalski M, Swilling M, von Weizsäcker EU, et al (2011) Decoupling Natural Resource Use and Environmental Impacts from Economic GrowthNo Title

Fourie J (2006) Economic infrastructure: A review of definitions, theory and empirics. South African J Econ 74:530-556. doi: 10.1111/j.1813-6982.2006.00086.x

Foxon TJ (2010) Stimulating investment in energy materials and technologies to combat climate change: an overview of learning curve analysis and niche market support. Philos Trans R Soc A Math Phys Eng Sci 368:3469-3483. doi: 10.1098/rsta.2010.0106

Fujisaka S, Escobar G, Veneklaas E (1998) Plant community diversity relative to human land uses in an Amazon forest colony. Biodivers Conserv 7:41-57. doi: 10.1023/A:1008855612209

Gaines BR (1998) The learning curves underlying convergence. Technol Forecast Soc Change 57:734. doi: 10.1016/S0040-1625(97)00078-4

Gaynor JFN (1948) omparative vperating Electric and ectric Motive. 67:231-235

Glisovic S, Stojiljkovic E, Stojiljkovic P (2015) The state of play in disseminating LCM practices in the Western Balkan region: the attitude of Serbian SMEs. Int J Life Cycle Assess. doi: 10.1007/s11367-015-0894-7

Global Footprint Network (2018) Ecological Footprint Explorer. http://data.footprintnetwork.org/\#/ Group World Bank Infrastructure Strategy Committee (2015) Transformation Through Infrastructure

Gschösser F, Wallbaum H (2013) Life cycle assessment of representative swiss road pavements for national roads with an accompanying life cycle cost analysis. Environ Sci Technol 47:8453-61. doi: 10.1021/es400309e

Gutman G, Janetos AC, Justice CO, et al (2004) Land change science 
Hertwich EG (2008) Consumption and the Rebound Effect: An Industrial Ecology Perspective. J Ind Ecol 9:85-98. doi: 10.1162/1088198054084635

Heshmati A, Lenz-Cesar F (2015) Policy simulation of firms' cooperation in innovation. Res Eval 24:293-311. doi: 10.1093/reseval/rvv011

Howarth RW (2008) Coastal nitrogen pollution: A review of sources and trends globally and regionally. Harmful Algae 8:14-20. doi: 10.1016/j.hal.2008.08.015

Huijbregts MAJ (1998) Application of uncertainty and variability in LCA. Int J Life Cycle Assess 3:273280. doi: 10.1007/BF02979835

Humphrey S, Chapagain A, Bourne G, et al (2008) Living Planet Report 2008. Gland

Hunkeler D, Rebitzer G, Jensen AA, Margni M (2001) Life cycle management: Bridging the gap between science and application. Int J ... 6:384-390. doi: 10.1007/BF02978870

IPCC (2007) Climate Change 2007: impacts, adaptation and vulnerability: contribution of Working Group II to the fourth assessment report of the Intergovernmental Panel. Cambridge University Press, Cambridge

IPCC (2012) Managing the Risks of Extreme Events and Disasters to Advance Climate Change Adaptation. Cambridge University Press, Cambridge

Jones D, Sakhel A, Buck M, Graichen P (2018) The European Power Sector in 2017. Agora Energiewende and Sandbag

Kaminsky JA, Faust KM (2017) Transitioning from a Human Right to an Infrastructure Service: Water, Wastewater, and Displaced Persons in Germany. Environ Sci Technol acs.est.7b03594. doi: 10.1021/acs.est.7b03594

Kemp R, Rip A, Schot JW (2001) Constructing Transition Paths Through the Management of Niches. Path Depend Creat 269-299

Kesztenbaum L, Rosenthal JL (2017) Sewers' diffusion and the decline of mortality: The case of Paris, 1880-1914. J Urban Econ 98:174-186. doi: 10.1016/j.jue.2016.03.001

Krantz J (2017) Reducing Carbon Dioxide Emissions in Transport Infrastructure Projects

Lal R (2004) Soil carbon sequestration to mitigate climate change. Geoderma 123:1-22. doi: 10.1016/j.geoderma.2004.01.032

Lambin EF, Meyfroidt P (2011) Global land use change, economic globalization, and the looming land scarcity. Proc Natl Acad Sci 108:3465-3472. doi: 10.1073/pnas.1100480108

Larsson J (2012) Mapping the Concept of Industrialized Bridge Construction

Law J (2016) infrastructure. A Dict. Account.

Lee JU, Han JH, Lee IB (2012) A multiobjective optimization approach for CCS infrastructure considering cost and environmental impact. Ind Eng Chem Res 51:14145-14157. doi: 10.1021/ie3009583

Lenferink S, Arts J, Tillema T, et al (2012) Early contractor involvement in dutch infrastructure development: Initial experiences with parallel procedures for planning and procurement. Manag Res Rev 12:4-42. doi: 10.1108/JOPP-12-01-2012

Liang Y, Liu L (2017) Simulating land-use change and its effect on biodiversity conservation in a watershed in northwest China. Ecosyst Heal Sustain 3:. doi: 10.1080/20964129.2017.1335933 
Liu G, Müller DB (2013) Mapping the global journey of anthropogenic aluminum: A trade-linked multilevel material flow analysis. Environ Sci Technol 47:11873-11881. doi:

10.1021/es4024404

Lopolito A, Morone P, Sisto R (2011) Innovation niches and socio-technical transition: A case study of bio-refinery production. Futures 43:27-38. doi: 10.1016/j.futures.2010.03.002

Lopolito A, Morone P, Taylor R (2013) Emerging innovation niches: An agent based model. Res Policy 42:1225-1238. doi: 10.1016/j.respol.2013.03.002

Meyfroidt P, Lambin EF, Erb KH, Hertel TW (2013) Globalization of land use: Distant drivers of land change and geographic displacement of land use. Curr Opin Environ Sustain 5:438-444. doi: 10.1016/j.cosust.2013.04.003

Milford RL, Pauliuk S, Allwood JM, Müller DB (2013) The roles of energy and material efficiency in meeting steel industry $\mathrm{CO} 2$ targets. Environ Sci Technol 47:3455-3462. doi: 10.1021/es3031424

Mitchell JFB (1989) The "greenhouse" effect and climate change. Am Geophys Union 27:115-139. doi: 10.1029/RG027i001p00115

Mohd Hasan MR, You Z (2015) Estimation of cumulative energy demand and green house gas emissions of ethanol foamed WMA using life cycle assessment analysis. Constr Build Mater 93:1117-1124. doi: 10.1016/j.conbuildmat.2015.05.029

NASA (2018) The consequences of climate change. https://climate.nasa.gov/effects/

Nelson G (2005) Drivers of ecosystem change: summary chapter. Ecosyst Hum Well-being Curr State Trends 1:73-76

Newbold T, Hudson LN, Hill SLL, et al (2015) Global effects of land use on local terrestrial biodiversity. Nature 520:45-50. doi: 10.1038/nature14324

Nielsen D, Raman D, Chattopadhyay G (2013) Life cycle management for railway bridge assets. Proc Inst Mech Eng Part F J Rail Rapid Transit 227:570-581. doi: 10.1177/0954409713501297

Nilsson-Linden $\mathrm{H}$, Baumann $\mathrm{H}$, Rosen $\mathrm{M}$, Diedrich A (2014) Organizing life cycle management in practice: challenges of a multinational manufacturing corporation. Int J Life Cycle Assess 15. doi: 10.1007/s11367-014-0818-y

NPRA (2018a) The E39 Coastal Highway Route. https://www.vegvesen.no/en/roads/Roads+and+bridges/Road+projects/e39coastalhighwayro ute. Accessed 4 Jun 2018

NPRA (2018b) BRUTUS - the management system. https://www.vegvesen.no/en/roads/Roads+and+bridges/Bridges. Accessed 10 Jun 2018

NPRA (2010) PMS 2010. 22

Olssen M, Codd JA, O’Neill A-M (2004) Education policy: globalization, citizenship and democracy

Oskin B (2017) Japan Earthquake \& Tsunami of 2011: Facts and Information. https://www.livescience.com/39110-japan-2011-earthquake-tsunami-facts.html

Palei T (2015) Assessing the Impact of Infrastructure on Economic Growth and Global Competitiveness. Procedia Econ Financ 23:168-175. doi: 10.1016/S2212-5671(15)00322-6

Pauliuk S, Wang T, Müller DB (2013) Steel all over the world: Estimating in-use stocks of iron for 200 countries. Resour Conserv Recycl 71:22-30. doi: 10.1016/j.resconrec.2012.11.008 
Pielke Sr. RA (2005) ATMOSPHERIC SCIENCE: Land Use and Climate Change. Science (80- ) 310:16251626. doi: $10.1126 /$ science. 1120529

Raven RPJM (2004) Implementation of manure digestion and co-combustion in the Dutch electricity regime: A multi-level analysis of market implementation in the Netherlands. Energy Policy 32:29-39. doi: 10.1016/S0301-4215(02)00248-3

Reid W V., Chen D, Goldfarb L, et al (2010) Earth system science for global sustainability: Grand challenges. Science (80- ) 330:916-917. doi: 10.1126/science.1196263

Rockström J, Steffen W, Noone K, et al (2009a) A safe operating space for humanity. Nature 461:472-5. doi: 10.1038/461472a

Rockström J, Steffen W, Noone K, et al (2009b) Planetary Boundaries : Exploring the safe operating space for humanity. 1-36. doi: 10.2174/1874282300802010217; Hare, B., Meinshausen, M., How much warming are we committed to and how much can be avoided? (2006) Climatic Change, 75, pp. 111-149; Hoegh-Guldberg, O., Mumby, P.J., Hooten, A.J., Steneck, R.S., Greenfield, P., Gomez, E., Harvell, C.D., Hatziolos, M.E., Coral reefs under rapid climate change and ocean acidification (2007) Science, 318, pp. 1737-1742; Hofmann, M., Schellnhuber, H.-J., Oceanic acidification affects marine carbon pump and triggers extended marine oxyge

Sachs W (1999) Planet Dialectics: explorations in environment and development. Zed Books, London

Sahely HR, Kennedy CA, Adams BJ (2005) Developing sustainability criteria for urban infrastructure systems. Can J Civ Eng 32:72-85. doi: 10.1139/104-072

Santos J, Ferreira A, Flintsch G, Cerezo V (2018) A multi-objective optimisation approach for sustainable pavement management. Struct Infrastruct Eng 2479:1-15. doi: 10.1080/15732479.2018.1436571

Schmidt JH, Weidema BP, Brandão M (2015) A framework for modelling indirect land use changes in Life Cycle Assessment. J Clean Prod 99:230-238. doi: 10.1016/j.jclepro.2015.03.013

Schot J, Geels FW (2008) Strategic niche management and sustainable innovation journeys: Theory, findings, research agenda, and policy. Technol Anal Strateg Manag 20:537-554. doi: 10.1080/09537320802292651

Schot J, Hoogma R, Elzen B (1994) Strategies for shifting technological systems. The case of the automobile system. Futures 26:1060-1076. doi: 10.1016/0016-3287(94)90073-6

Senge PM, Carstedt G (2001) Innovating Our Way to the Next Industrial Revolution. MIT Sloan Manag Rev 42:24-38. doi: 10.1126/science.167.3926.1673

Smith DW, Bangs EE, Oakleaf JK, et al (2010) Survival of Colonizing Wolves in the Northern Rocky Mountains of the United States, 1982-2004. J Wildl Manage 74:620-634. doi: 10.2193/2008584

Sonnemann G, Gemechu ED, Remmen A, et al (2015) Life Cycle Management: Implementing Sustainability in Business Practice. 7-22. doi: 10.1007/978-94-017-7221-1

Sonnemann G, Leeuw B de (2006) Life Cycle Management in Developing Countries: State of the Art and Outlook. Int J Life Cycle Assess 11:123-126. doi: 10.1065/Ica2006.04.020

Sonnemann G, Margni M (eds) (2015) Life Cycle Management. Springer Netherlands, Dordrecht

Sonnemann GW, Solgaard A, Saur K, et al (2001) Life cycle management: UNEP-workshop. Int J Life Cycle Assess 6:325-333. doi: 10.1007/BF02978862 
STA (2018a) BaTMan management system. https://batman.trafikverket.se/externportal. Accessed 10 Jun 2018

STA (2018b) PMSV3. https://pmsv3.trafikverket.se/. Accessed 10 Jun 2018

Steffen W, Richardson K, Rockström J, et al (2015) Planetary boundaries: Guiding human development on a changing planet. Science (80- ) 347:. doi: 10.1126/science.1259855

Thorson JT, Jannot J, Somers K (2017) Using spatio-temporal models of population growth and movement to monitor overlap between human impacts and fish populations. J Appl Ecol 54:577-587. doi: 10.1111/1365-2664.12664

Tol RSJ (2018) The Economic Impacts of Climate Change. Rev Environ Econ Policy 12:4-25. doi: $10.1093 /$ reep/rex027

Truffer B, Metzner A, Ag D (2002) The Coupling of Viewing and Doing

Ugwu OO, Haupt TC (2007) Key performance indicators and assessment methods for infrastructure sustainability-a South African construction industry perspective. Build Environ 42:665-680. doi: 10.1016/j.buildenv.2005.10.018

UNEP (2011) Visions For Change

UNEP/SETAC (2007) Life cycle management: a business guide to sustainability acknowledgements

UNESCAP (2007) Toward an Asian Integrated Transport Network, Monograph Series on Managing Globalization

UNFCCC (2016) 20 Years of Effort and Achievement. http://unfccc.int/timeline/

UNFCCC (1997) Summary of the Kyoto Protocol. http://bigpicture.unfccc.int/\#content-the-parisagreemen

UNFCCC (2015) Summary of the Paris Agreement. http://bigpicture.unfccc.int/\#content-the-parisagreemen

UNFPA (2007) The State of the World Population 2007 - Unleashing The Potential of Urban Growth. Link Popul Poverty Dev 1-34. doi: ISBN 978-0-89714-807-8

United Nations (1992) The Earth Summit. http://www.un.org/geninfo/bp/enviro.html

United Nations (2016) The Sustainable Development Goals Report

United Nations (2017a) The Sustainable Development Goals Report

United Nations (2018a) Sustainable Development Goals. https://sustainabledevelopment.un.org/sdgs

United Nations (2015) World Urbanization Prospects

United Nations (2017b) World Population Prospects: Key Findings and Advance Tables

United Nations (2017c) World Population Prospects 2017. https://esa.un.org/unpd/wpp/

United Nations (2018b) World Urbanization Prospects. https://esa.un.org/unpd/wup/

Van Den Ende J, Kemp R (1999) Technological transformations in history: How the computer regime grew out of existing computing regimes. Res Policy 28:833-851. doi: 10.1016/S00487333(99)00027-X

Verbong G, Geels F (2007) The ongoing energy transition: Lessons from a socio-technical, multi-level 
analysis of the Dutch electricity system (1960-2004). Energy Policy 35:1025-1037. doi: 10.1016/j.enpol.2006.02.010

Winch GM (2003) Models of manufacturing and the construction process: The genesis of reengineering construction. Build Res Inf 31:107-118. doi: 10.1080/09613210301995

Wrisberg N, Udo de Haes HA, Triebswetter U, et al (2002) Analytical tools for environmental design and management in a systems perspective. . 10:6221

Wu Z, Flintsch G, Ferreira A, Picado-Santos L de (2012) Framework for Multiobjective Optimization of Physical Highway Assets Investments. J Transp Eng 138:1411-1421. doi: 10.1061/(ASCE)TE.1943-5436.0000458

WWF (2016) Living planet report: risk and resilience in a new era

Zhao G, Liu J, Kuang W, et al (2015) Disturbance impacts of land use change on biodiversity conservation priority areas across China: 1990-2010. J Geogr Sci 25:515-529. doi: $10.1007 / \mathrm{s} 11442-015-1184-9$ 